\title{
Poorer breast cancer survival outcomes in males than females might be attributable to tumor subtype
}

\author{
Qi Wu ${ }^{1, *}$, Juanjuan $\mathrm{Li}^{1 *}$, Shan Zhu ${ }^{1}$, Juan $\mathbf{W u}^{2}$, Xiang $\mathrm{Li}^{3}$, Qian Liu ${ }^{1}$, Wen Wei ${ }^{1}$ and \\ Shengrong Sun ${ }^{1}$ \\ ${ }^{1}$ Department of Breast and Thyroid Surgery, Renmin Hospital of Wuhan University, Wuhan, Hubei, P. R. China \\ ${ }^{2}$ Department of Pathology, Renmin Hospital of Wuhan University, Wuhan, Hubei, P. R. China \\ ${ }^{3}$ Department of Breast Surgery, Hubei Cancer Hospital, Wuhan, Hubei, P. R. China \\ * These authors contributed equally to this work
}

Correspondence to: Shengrong Sun, email: sun137@sina.com

Keywords: breast cancer, male breast cancer, SEER data

Received: May 31, $2016 \quad$ Accepted: September 04, $2016 \quad$ Published: September 15, 2016

\section{ABSTRACT}

Background \& Aims: Substantial controversy exists regarding the differences in tumor subtypes between male breast cancer (MBC) and female breast cancer (FBC). This is the largest population-based study to compare MBC and FBC patients.

Methods: Using data obtained by the Surveillance, Epidemiology, and End Results (SEER) program from 2010-2012, a retrospective, population-based cohort study was conducted to investigate tumor subtype-specific differences in various characteristics, overall survival (OS) and breast cancer-specific mortality (BCSM) between males and females.

Results: In all, 181,814 BC patients (1,516 male and 180,298 female) were eligible for this study. The male patients were more likely to be black, older, and have lower histological grades, more advanced stages, larger tumors, more lymph node and distant metastases and human epidermal growth factor receptor 2 (HER2)negative tumors (each $p<0.05$ ). A matched analysis showed that the 2 -year 05 was $91.2 \%$ and $93.7 \%$ and that the BCSM was $2.2 \%$ and $2.5 \%$ for male and female patients, respectively. The univariate analysis showed that male triple-negative (TN), hormone receptor (HoR)-positive/HER2-positive and HoR-positive/HER2-negative patients had poorer OS $(p<0.01)$. Meanwhile, the HoR-positive/HER2-positive and TN subtypes were associated with a higher BCSM in MBC patients $(p<0.01)$. The multivariate analysis revealed that TN MBC patients had poorer OS and BCSM $(p<0.05)$. Simultaneously, the results showed that male patients in the HoR-positive/ HER2-negative subgroup were less likely to die of BC when adjusting for other factors $(p<0.05)$.

Conclusions: The analysis of 2-year OS and BCSM among the BC subtypes showed clear differences between MBC and FBC patients with the TN subtype; these differences warrant further investigation

\section{INTRODUCTION}

Male breast cancer (MBC) is an uncommon disease, constituting less than $1 \%$ of all BCs and approximately $0.2 \%$ of all male cancers $[1,2]$. In contrast to the incidence of female breast cancer (FBC), the incidence of $\mathrm{MBC}$ has been steadily increasing over the past 3 decades [3-5]. The low incidence of the disease has resulted in only a superficial knowledge of its etiology, biological behavior, and treatment. The prognostic factors, epidemiological factors, and behavior of $\mathrm{BC}$ are different for males than females [3]. As more data on the tumor biology of MBC emerges, it is becoming clear that $\mathrm{MBC}$ is a unique disease requiring its own trials and treatment guidelines.

Although the mortality and survival rates have been significantly improved for both $\mathrm{MBC}$ and $\mathrm{FBC}$ patients, more progress has been made in $\mathrm{FBC}$ than $\mathrm{MBC}[6,7]$. Because of the rarity of $\mathrm{MBC}$, no randomized trials have been possible, and most information is derived from retrospective studies. Several studies have compared 
Table 1: Characteristics of male and matched female patients with breast cancer

\begin{tabular}{|c|c|c|c|}
\hline Variables & \begin{tabular}{|l|} 
Female \\
$N=180298(\%)$
\end{tabular} & \begin{tabular}{|l|} 
Male \\
$N=1516(\%)$ \\
\end{tabular} & $P$ \\
\hline Follow-up time, months & $15.88 \pm 10.34$ & $15.5 \pm 10.44$ & \\
\hline Age at diagnosis, years & & & $<0.01$ \\
\hline$<35$ & $3329(1.8)$ & $12(0.8)$ & \\
\hline $35-49$ & $33520(18.6)$ & \begin{tabular}{|l|}
$147(9.7)$ \\
\end{tabular} & \\
\hline $50-64$ & $67645(37.5)$ & $455(30.0)$ & \\
\hline$\geq 65$ & $75804(42.1)$ & $902(59.5)$ & \\
\hline Race & & & $<0.01$ \\
\hline white & $143614(79.7)$ & $1212(79.9)$ & \\
\hline Black & 19763(11.0) & $213(14.1)$ & \\
\hline Other & $15432(8.6)$ & $78(5.1)$ & \\
\hline Unknown & $1489(0.8)$ & $13(0.9)$ & \\
\hline Grade & & & $<0.01$ \\
\hline Well & $38292(21.2)$ & $179(11.8)$ & \\
\hline Moderately & $73061(40.5)$ & $713(47.0)$ & \\
\hline Poorly & $54471(30.2)$ & $501(33.0)$ & \\
\hline Undifferentiated & $905(0.5)$ & $4(0.3)$ & \\
\hline Unknown & $13569(7.5)$ & $119(7.8)$ & \\
\hline Stage & & & $<0.01$ \\
\hline$I$ & 98878(54.8) & $632(41.8)$ & \\
\hline II & $55199(30.6)$ & $560(36.9)$ & \\
\hline III & $18995(10.5)$ & $252(16.6)$ & \\
\hline IV & $7006(3.9)$ & $72(4.7)$ & \\
\hline Unknown & $220(0.1)$ & - & \\
\hline Tumor size & & & $<0.01$ \\
\hline T0/T1 & $103334(57.3)$ & $694(45.8)$ & \\
\hline T2 & $50479(28.0)$ & $566(37.3)$ & \\
\hline T3 & $18047(10.0)$ & $42(2.7)$ & \\
\hline T4 & $8218(4.6)$ & $130(8.5)$ & \\
\hline NA & $220(0.1)$ & $84(5.5)$ & \\
\hline Node stage & & & $<0.01$ \\
\hline No & $119544(66.3)$ & $836(55.1)$ & \\
\hline N1 & $39702(22.0)$ & $434(28.6)$ & \\
\hline N2 & $9384(5.2)$ & $131(8.6)$ & \\
\hline N3 & 6113(3.4) & $72(4.7)$ & \\
\hline NX & $5335(3.0)$ & $43(2.8)$ & \\
\hline NA & $220(0.1)$ & - & \\
\hline Distant metastasis & & & 0.02 \\
\hline M0 & $170033(94.3)$ & $1411(93.1)$ & \\
\hline M1 & $10045(5.6)$ & $105(6.9)$ & \\
\hline NA & $220(0.1)$ & - & \\
\hline Laterality & & & 0.11 \\
\hline Left & $90962(50.5)$ & $797(52.6)$ & \\
\hline Right & $88083(48.9)$ & 703(46.4) & \\
\hline Paired & $1046(0.6)$ & $12(0.8)$ & \\
\hline Bilateral & $104(0.1)$ & - & \\
\hline Unknown & $103(0.1)$ & $4(0.3)$ & \\
\hline HER2 & & & $<0.01$ \\
\hline \begin{tabular}{|l|} 
Negative \\
\end{tabular} & 138954(77.1) & 1191(78.6) & \\
\hline Positive & $23990(13.3)$ & $153(10.1)$ & \\
\hline
\end{tabular}




\begin{tabular}{|l|l|l|l|}
\hline Borderline & $4194(2.3)$ & $47(3.1)$ & \\
\hline Unknown & $13160(7.3)$ & $125(8.2)$ & \\
\hline Radiotherapy & & & $<0.01$ \\
\hline No & $92832(51.5)$ & $1109(73.2)$ & \\
\hline Yes & $86039(47.7)$ & $396(26.1)$ & \\
\hline Unknown & $1427(0.8)$ & $11(0.7)$ & \\
\hline Status & & & $<0.01$ \\
\hline Alive & $168929(93.7)$ & $1382(91.2)$ & \\
\hline Dead & $11369(6.3)$ & $134(8.8)$ & \\
\hline
\end{tabular}

y years

$\mathrm{MBC}$ and $\mathrm{FBC}$ and have found that $\mathrm{MBC}$ was not only associated with a worse prognosis but also showed more advanced stages and older ages at diagnosis, inappropriate staging, increased comorbidities, and more aggressive tumor biology [8-10]. Other studies have shown no association between MBC and survival and have suggested that patient sex does not influence mortality [11-13]. Thus, there is no consensus on the relationship between sex and prognosis in BC. Given that treatment strategy and patient management depend on prognostic variables, we used data from the National Cancer Institute's Surveillance, Epidemiology, and End Results (SEER) program to analyze the association of each tumor subtype with overall survival (OS) and breast cancer-specific mortality (BCSM) at diagnosis for males and females diagnosed with $\mathrm{BC}$.

\section{RESULTS}

\section{Patient characteristics}

A total of 1,516 MBC and 180,298 FBC patients were eligible during the 2010-2012 study period. We excluded 710 patients whose survival times were classified as unknown from the analysis. A total of 1,339 $\mathrm{MBC}$ and 162,448 FBC patients had tumor subtype information available and were included in this study.

Differences in patient demographics, cancer characteristics, treatments, and outcomes between the two groups are summarized in Table 1 . In all, $59.5 \%$ of the MBC patients were $\geq 65$ years old at the time of diagnosis. Males were more likely to be black and at more advanced stages (each $p<0.01$ ). Biological tumor characteristics also differed significantly between the sexes. $\mathrm{MBC}$ was more likely to be lower in grade, larger in size, have more lymph node and distant metastases and be human epidermal growth factor receptor 2 (HER2) negative (each $p<0.05$ ). Males were also less likely to receive radiation than females $(p<0.01)$.

\section{Impact of tumor subtype on OS in MBC and FBC}

A Kaplan-Meier analysis was used to determine OS in the groups based on sex. Individual survival curves for the four subgroups were generated (Figure 1). As expected, male patients exhibited poorer survival rates than female patients $(p<0.01)$. Unexpectedly, the stratified analysis indicated that the survival rates were similar for $\mathrm{MBC}$ and FBC patients in the hormone receptor (HoR)-negative/ HER2-positive group, whereas in the other groups, OS was better for FBC patients than MBC patients $(p<0.01)$.

We performed univariate and multivariate analyses based on the Kaplan-Meier results. In the univariate analysis, age at diagnosis, sex, race, tumor grade, laterality, tumor stage, tumor size, node stage, distant metastasis, HER2 status and history of radiation were all significantly associated with OS $(p<0.05)$. A multivariate analysis using the Cox regression model was also performed. All the factors mentioned above were identified as independent prognostic factors (Table 2), including age at diagnosis $(50-64$, hazard ratio $(\mathrm{HR})=1.678(1.391$, $2.024) ; \geq 65, \mathrm{HR}=3.772(3.133,4.541)), \operatorname{sex}(\mathrm{HR}=0.923$ $(0.778,1.095))$, race (black, HR $=1.34(1.275,1.408))$, grade (moderately differentiated, HR $=1.139(1.062$, 1.221); poorly differentiated, $\mathrm{HR}=1.902$ (1.774, 2.04); undifferentiated, $\mathrm{HR}=2.037(1.673,2.48))$, tumor stage (II, HR = $1.134(1.047,1.229) ;$ III, HR = 2.862 (2.606, 3.143); IV, HR $=2.405(2.165,2.672))$, tumor size $(\mathrm{T} 2$, $\mathrm{HR}=1.628(1.513,1.752) ; \mathrm{T} 3, \mathrm{HR}=2.296(2.134,2.47)$; $\mathrm{T} 4, \mathrm{HR}=1.875(1.712,2.053))$, node stage $(\mathrm{N} 1, \mathrm{HR}=$ $1.133(1.078,1.919) ; \mathrm{N} 2, \mathrm{HR}=1.183(1.093,1.28) ; \mathrm{N} 3$, $\mathrm{HR}=1.498(1.397,1.607))$, distant metastasis $(\mathrm{M} 1, \mathrm{HR}$ $=2.857(2.668,3.06))$, laterality (bilateral, $\mathrm{HR}=1.167$ $(1.053,1.294)$ ), HER2 status (positive, HR $=1.507$ (1.425, 1.594); borderline, $\mathrm{HR}=1.09(0.977,1.217))$ and history of radiation (no, $\mathrm{HR}=1.124(0.968,1.306)$ ).

Table 3 shows a summary of OS in MBC and FBC as determined by the subgroup analysis. After a median follow-up period of 15 months (range, 0-35 months), $91.2 \%$ of men and $93.7 \%$ of women were alive in the overall cohort. The univariate analysis of OS according to tumor subtype showed significant differences between $\mathrm{MBC}$ and $\mathrm{FBC}$; lower survival was observed in males 
Table 2: Cox proportional hazards regression model analysis of overall survival

\begin{tabular}{|c|c|c|c|c|}
\hline \multirow{2}{*}{ Variables } & \multicolumn{2}{|l|}{ Univariate analysis } & \multicolumn{2}{|c|}{ Multivariate analysis } \\
\hline & HR $(95 \%$ CI) & $P$-value & HR (95\% CI) & $P$-value \\
\hline \multicolumn{5}{|l|}{ Age at diagnosis, $y$} \\
\hline$<35$ & Reference & & Reference & \\
\hline $35-49$ & $0.92(0.759,1.116)$ & 0.399 & $1.174(0.968,1.424)$ & 0.104 \\
\hline $50-64$ & $1.245(1.032,1.501)$ & 0.022 & $1.678(1.391,2.024)$ & $<0.001$ \\
\hline$\geq 65$ & $2.859(2.376,3.44)$ & $<0.001$ & $3.772(3.133,4.541)$ & $<0.001$ \\
\hline Sex & $1.431(1.207,1.697)$ & $<0.001$ & $0.923(0.778,1.095)$ & 0.359 \\
\hline \multicolumn{5}{|l|}{ Race } \\
\hline white & Reference & & Reference & \\
\hline Black & $1.631(1.553,1.713)$ & $<0.001$ & $1.34(1.275,1.408)$ & $<0.001$ \\
\hline Other & $0.665(0.613,0.721)$ & $<0.001$ & $0.753(0.695,0.817)$ & $<0.001$ \\
\hline Unknown & $0.61(0.452,0.823)$ & 0.001 & $0.456(0.338,0.616)$ & $<0.001$ \\
\hline \multicolumn{5}{|l|}{ Grade } \\
\hline Well & Reference & & Reference & \\
\hline Moderately & $1.519(1.418,1.627)$ & $<0.001$ & $1.139(1.062,1.221)$ & $<0.001$ \\
\hline Poorly & $2.931(2.743,3.132)$ & $<0.001$ & $1.902(1.774,2.04)$ & $<0.001$ \\
\hline Undifferentiated & $4.541(3.744,5.507)$ & $<0.001$ & $2.037(1.673,2.48)$ & $<0.001$ \\
\hline Unknown & $8.102(7.551,8.692)$ & $<0.001$ & $1,821(1.682,1.972)$ & $<0.001$ \\
\hline \multicolumn{5}{|l|}{ Stage } \\
\hline I & Reference & & Reference & \\
\hline II & $1.835(1.734,1.942)$ & $<0.001$ & $1.134(1.047,1.229)$ & 0.002 \\
\hline III & $3.422(2.788,4.088)$ & $<0.001$ & $2.862(2.606,3.143)$ & $<0.001$ \\
\hline IV & $9.755(9.133,10.419)$ & $<0.001$ & $2.405(2.165,2.672)$ & $<0.001$ \\
\hline Unknown & $9.757(7.129,12.859)$ & $<0.001$ & $4.822(3.565,6.521)$ & $<0.001$ \\
\hline \multicolumn{5}{|l|}{ Tumor size } \\
\hline T0/T1 & Reference & & Reference & \\
\hline T2 & $2.462(2.339,2.592)$ & $<0.001$ & $1.628(1.513,1.752)$ & $<0.001$ \\
\hline T3 & $7.843(7.454,8.252)$ & $<0.001$ & $2.296(2.134,2.47)$ & $<0.001$ \\
\hline T4 & $8.863(6.601,11.90)$ & $<0.001$ & $1.875(1.712,2.053)$ & $<0.001$ \\
\hline \multicolumn{5}{|l|}{ Node stage } \\
\hline No & Reference & & Reference & \\
\hline N1 & $2.013(1.924,2.107)$ & $<0.001$ & $1.133(1.078,1.919)$ & $<0.001$ \\
\hline $\mathbf{N 2}$ & $2.367(2.202,2.544)$ & $<0.001$ & $1.183(1.093,1.28)$ & $<0.001$ \\
\hline N3 & $4.397(4.109,4.706)$ & $<0.001$ & $1.498(1.397,1.607)$ & $<0.001$ \\
\hline $\mathbf{N X}$ & $5.844(4.357,7.838)$ & $<0.001$ & $1.06(0.978,1.15)$ & 0.156 \\
\hline \multicolumn{5}{|l|}{ Distant metastasis } \\
\hline M0 & Reference & & Reference & \\
\hline M1 & $5.158(3.848,6.914)$ & $<0.001$ & $2.857(2.668,3.06)$ & $<0.001$ \\
\hline \multicolumn{5}{|l|}{ Laterality } \\
\hline Left & Reference & & Reference & \\
\hline Right & $0.961(0.925,0.997)$ & 0.145 & $0.953(0.918,0.989)$ & 0.102 \\
\hline Paired & $1.163(1.126,1.297)$ & 0.146 & $0.905(0.662,1.236)$ & 0.530 \\
\hline Bilateral & $2.332(2.105,2.371)$ & $<0.001$ & $1.167(1.053,1.294)$ & 0.003 \\
\hline Unknown & $1.206(0.856,1.698)$ & 0.285 & $1.064(0.776,1.457)$ & 0.701 \\
\hline \multicolumn{5}{|l|}{ HER2 } \\
\hline Negative & Reference & & Reference & \\
\hline Positive & $3.635(3.471,3.807)$ & $<0.001$ & $1.507(1.425,1.594)$ & $<0.001$ \\
\hline Borderline & $1.464(1.312,1.634)$ & $<0.001$ & $1.09(0.977,1.217)$ & $<0.001$ \\
\hline Unknown & $1.178(1.114,1.246)$ & $<0.001$ & $0.832(0.786,0.881)$ & 0.123 \\
\hline \multicolumn{5}{|l|}{ Radiotherapy } \\
\hline Yes & Reference & & Reference & \\
\hline No & $1.908(1.6472 .211)$ & $<0.001$ & $1.124(0.968,1.306)$ & $<0.001$ \\
\hline
\end{tabular}

HER2 human epidermal growth factor receptor 2; HoR hormone receptor; 
Table 3: Overall survival according to tumor subtypes between MBC and FBC

\begin{tabular}{|l|l|l|l|l|l|l|}
\hline Tumor subtype & $\begin{array}{l}\text { Female } \\
(\%)\end{array}$ & $\begin{array}{l}\text { Male } \\
(\%)\end{array}$ & cHR 95\% CI & $\boldsymbol{P}$ & aHR 95\% CI & $\boldsymbol{P}$ \\
\hline $\begin{array}{l}\text { HoR-positive } \\
\text { /HER2-negative }\end{array}$ & 95.8 & 93.8 & $1.496(1.186,1.888)$ & $<0.01$ & $0.864(0.684,1.092)$ & 0.221 \\
\hline $\begin{array}{l}\text { HoR-positive } \\
\text { /HER2-positive }\end{array}$ & 95.0 & 85.8 & $2.763(1.773,4.305)$ & $<0.01$ & $1.523(0.973,2.383)$ & 0.066 \\
\hline $\begin{array}{l}\text { HoR-negative } \\
\text { /HER2-positive }\end{array}$ & 91.6 & 83.3 & $2.186(0.545,8.761)$ & 0.26 & $1.138(0.28,4.623)$ & 0.857 \\
\hline Triple negative & 89.0 & 77.4 & $3.113(1.482,6.539)$ & $<0.01$ & $2.251(1.058,4.787)$ & 0.035 \\
\hline
\end{tabular}

Reference group for each model was 'women'.

HER2 human epidermal growth factor receptor 2; HoR hormone receptor; cHR: crude hazard ratio; CI: confidence interval; aHR: adjusted hazard ratio (adjusted for age at diagnosis, race, grade, stage, tumor stage, node stage, distant metastasis, laterality and radiation).

than females with the TN (2-year OS: 77.4\%, $p<0.01$ ), HoR-positive/HER2-positive (2-year OS: $85.8 \%, p<0.01$ ) and HoR-positive/HER2-negative subtypes (2-year OS: $93.8 \%, p<0.01)$. The results of the multivariate analysis were somewhat inconsistent with these findings, as they showed decreased survival in males only for the TN subtype $(\mathrm{HR}=2.251(1.058,4.787), p<0.05)$.
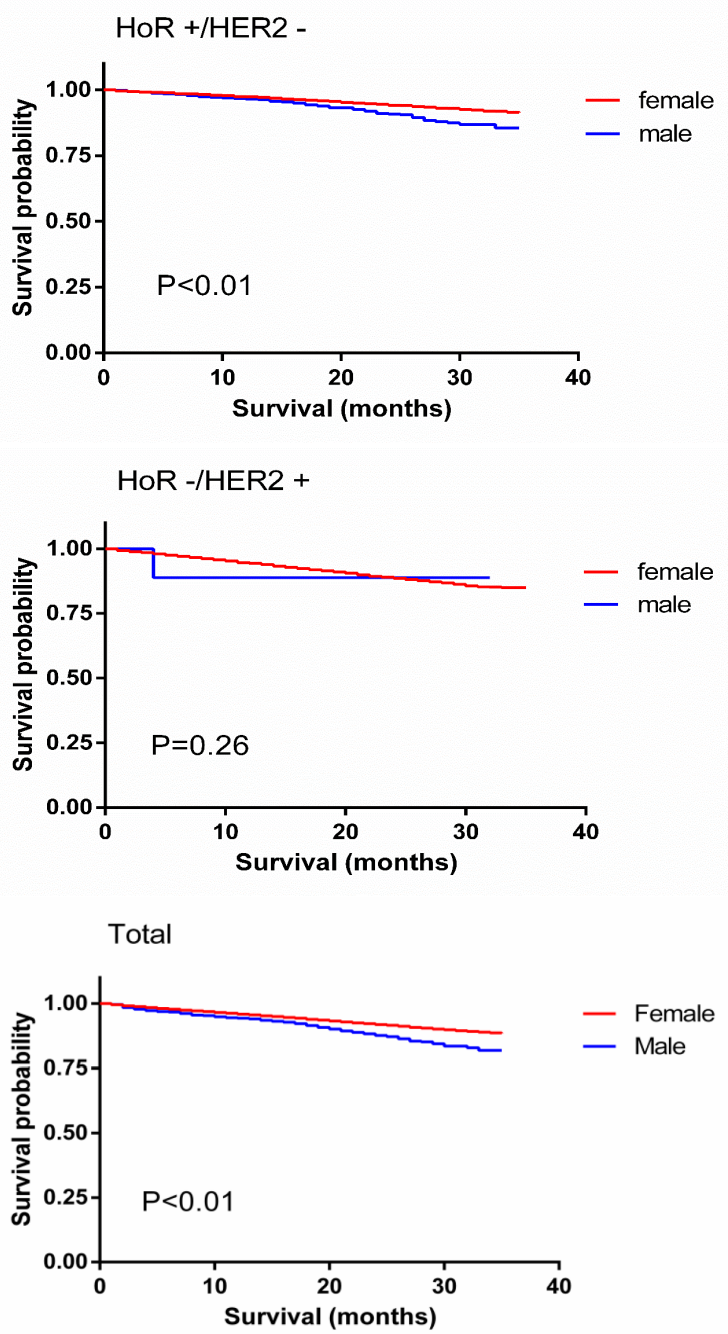

\section{Impact of tumor subtype on BCSM in $\mathrm{MBC}$ and FBC}

A Kaplan-Meier analysis was used to determine BCSM in the groups based on sex. Individual survival curves for the four subgroups were generated (Figure 2).
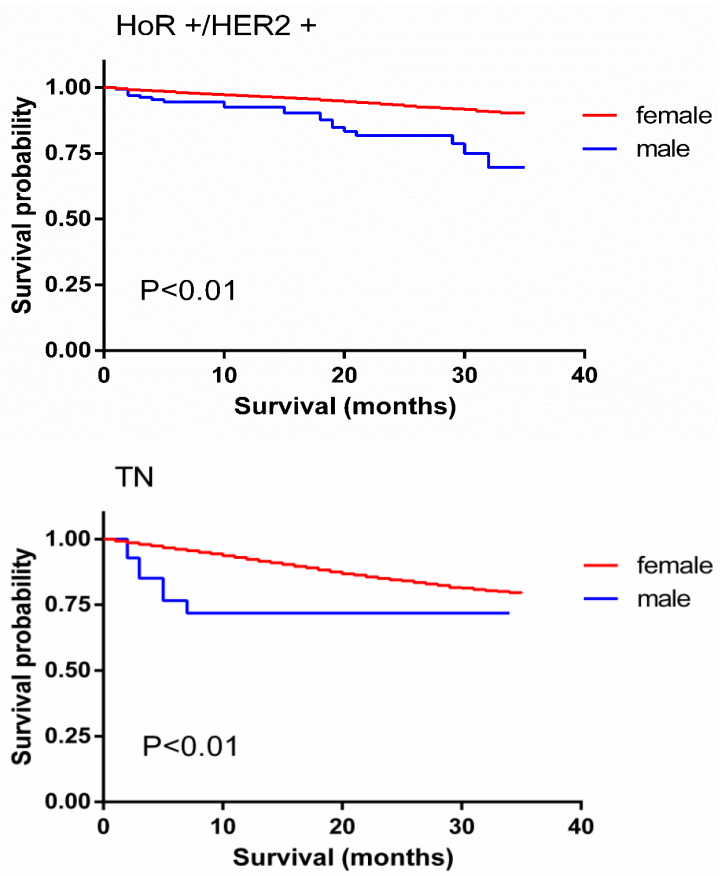

Figure 1: Overall survival curves of male matched with female breast cancer patients. 
Table 4: Cox proportional hazards regression model analysis of breast cancer-specific mortality

\begin{tabular}{|c|c|c|c|c|}
\hline \multirow{2}{*}{ Variables } & \multicolumn{2}{|c|}{ Univariate analysis } & \multicolumn{2}{|c|}{ Multivariate analysis } \\
\hline & HR $(95 \%$ CI) & $P$-value & HR $(95 \%$ CI) & $P$-value \\
\hline \multicolumn{5}{|l|}{ Age at diagnosis, $y$} \\
\hline$<35$ & Reference & & Reference & \\
\hline $35-49$ & $0.784(0.631,0.974)$ & 0.028 & $1.082(0.871,1.344)$ & 0.475 \\
\hline $50-64$ & $0.934(0.757,1.151)$ & 0.021 & $1.355(1.099,1.672)$ & 0.005 \\
\hline$\geq 65$ & $1.468(1.194,1.808)$ & $<0.001$ & $2.337(1.897,2.879)$ & $<0.001$ \\
\hline Sex & $0.931(0.685,1.266)$ & 0.21 & $0.721(0.53,1.081)$ & 0.073 \\
\hline \multicolumn{5}{|l|}{ Race } \\
\hline white & Reference & & Reference & \\
\hline Black & $1.951(1.824,2.086)$ & $<0.001$ & $1.346(1.258,1.441)$ & 0.001 \\
\hline Other & $0.706(0.629,0.792)$ & $<0.001$ & $0.768(0.684,0.862)$ & $<0.001$ \\
\hline Unknown & $0.656(0.431,0.997)$ & 0.048 & $0.477(0.313,0.981)$ & 0.031 \\
\hline \multicolumn{5}{|l|}{ Grade } \\
\hline Well & Reference & & Reference & \\
\hline Moderately & $3.045(2.63,3.526)$ & $<0.001$ & $1.848(1.594,2.142)$ & $<0.001$ \\
\hline Poorly & $8.836(7.677,10.171)$ & $<0.001$ & $3.868(3.347,4.471)$ & $<0.001$ \\
\hline Undifferentiated & $13.544(10.238,17.917)$ & $<0.001$ & $3.763(2.833,4.999)$ & $<0.001$ \\
\hline Unknown & $24.039(20.804,27.778)$ & $<0.001$ & $3.35(2.871,3.91)$ & $<0.001$ \\
\hline \multicolumn{5}{|l|}{ Stage } \\
\hline I & Reference & & Reference & \\
\hline II & $1.11(0.90-1.36)$ & $<0.001$ & $1.20(0.98-1.48)$ & $<0.001$ \\
\hline III & $1.77(1.18-2.67)$ & $<0.001$ & $1.72(1.15-2.61)$ & $<0.001$ \\
\hline IV & $2.19(1.88-2.59)$ & $<0.001$ & $2.19(1.88-2.60)$ & $<0.001$ \\
\hline \multicolumn{5}{|l|}{ Unknown } \\
\hline \multicolumn{5}{|l|}{ Tumor size } \\
\hline T0/T1 & Reference & & Reference & \\
\hline T2 & $4.711(4.295,5.167)$ & $<0.001$ & $2.919(2.651,3.214)$ & $<0.001$ \\
\hline T3 & $8.751(7.874,9.726)$ & $<0.001$ & $3.139(2.797,3.523)$ & $<0.001$ \\
\hline T4 & $9.517(8.519,10.291)$ & $<0.001$ & $6.984(5.211,8.963)$ & $<0.001$ \\
\hline NA & $3.73(2.944,4.794)$ & $<0.001$ & $5.882(5.23,6.615)$ & $<0.001$ \\
\hline \multicolumn{5}{|l|}{ Node stage } \\
\hline No & Reference & & Reference & \\
\hline N1 & $4.327(4.046,4.628)$ & $<0.001$ & $1.692(1.572,1.822)$ & $<0.001$ \\
\hline $\mathbf{N 2}$ & $4.802(4.354,5.297)$ & $<0.001$ & $1.643(1.48,1.824)$ & $<0.001$ \\
\hline N3 & $6.501(5.846,7.229)$ & $<0.001$ & $1.553(1.386,1.74)$ & $<0.001$ \\
\hline NX & $12.241(10.525,14.099)$ & $<0.001$ & $2.136(1.931,2.362)$ & $<0.001$ \\
\hline $\mathbf{N A}$ & $4.616(2.478,8.598)$ & $<0.001$ & $1.806(1.428,1.515)$ & 0.502 \\
\hline \multicolumn{5}{|l|}{ Distant metastasis } \\
\hline M0 & Reference & & Reference & \\
\hline M1 & $12.699(11.519,13.922)$ & $<0.001$ & $5.967(5.599,6.359)$ & $<0.001$ \\
\hline \multicolumn{5}{|l|}{ Laterality } \\
\hline Left & Reference & & Reference & \\
\hline Right & $0.957(0.906,1.011)$ & 0.118 & $0.968(0.916,1.022)$ & 0.239 \\
\hline Paired & $1.493(1.529,2.69)$ & 0.551 & $1.399(1.227,1.595)$ & 0.355 \\
\hline Bilateral & $1.425(0.844,1.823)$ & 0.025 & $1.545(1.37,1.804)$ & 0.035 \\
\hline Unknown & $1.263(0.709,1.645)$ & 0.138 & $1.16(0.79,1.705)$ & 0.449 \\
\hline \multicolumn{5}{|l|}{ HER2 } \\
\hline Negative & Reference & & Reference & \\
\hline Positive & $1.344(1.243,1.452)$ & $<0.001$ & $1.713(1.658,1.771)$ & $<0.001$ \\
\hline Borderline & $1.475(1.254,1.734)$ & $<0.001$ & $1.075(0.914,1.264)$ & 0.385 \\
\hline Unknown & $1.350(1.296,1.415)$ & $<0.001$ & $1.586(1.465,1.716)$ & $<0.001$ \\
\hline \multicolumn{5}{|l|}{ Radiotherapy } \\
\hline Yes & Reference & & Reference & \\
\hline No & $2.454(2.027,2.972)$ & $<0.001$ & $2.486(2.223,2.805)$ & $<0.001$ \\
\hline
\end{tabular}


Unexpectedly, male and female patients exhibited similar survival rates; additionally, the stratified analysis showed similar survival rates for $\mathrm{MBC}$ and $\mathrm{FBC}$ in the HoRpositive/HER2-negative and HoR-negative/HER2-positive groups, whereas BCSM was increased for MBC compared to $\mathrm{FBC}$ in the HoR-positive/HER2-positive and TN groups $(p=0.016, p<0.01)$.

Univariate and multivariate analyses were performed based on the Kaplan-Meier results. In the univariate analysis, age at diagnosis, race, tumor grade, laterality, tumor stage, tumor size, node stage, distant metastasis, HER2 status and history of radiation were significantly associated with $\operatorname{BCSM}(p<0.05)$. The multivariate analysis was performed using the Cox regression model. All the factors mentioned above were identified as independent prognostic factors (Table 4), including age at diagnosis (50-64, HR $=1.355$ (1.099, $1.672) ; \geq 65, \mathrm{HR}=2.337(1.897,2.879))$, race (black, HR

HoR +/HER2 -

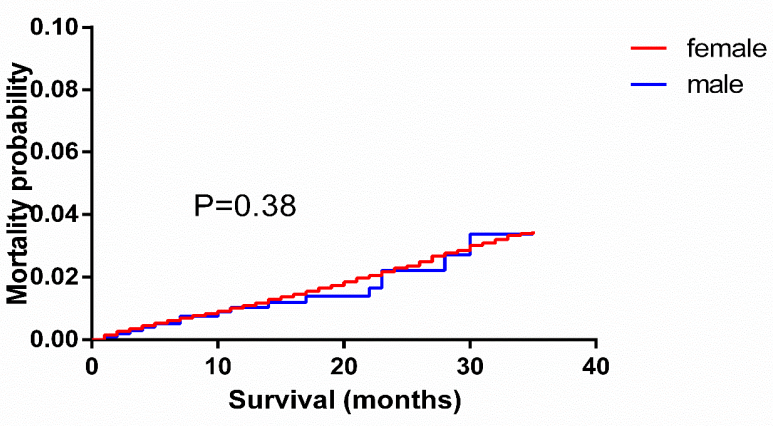

HoR -/HER2 +
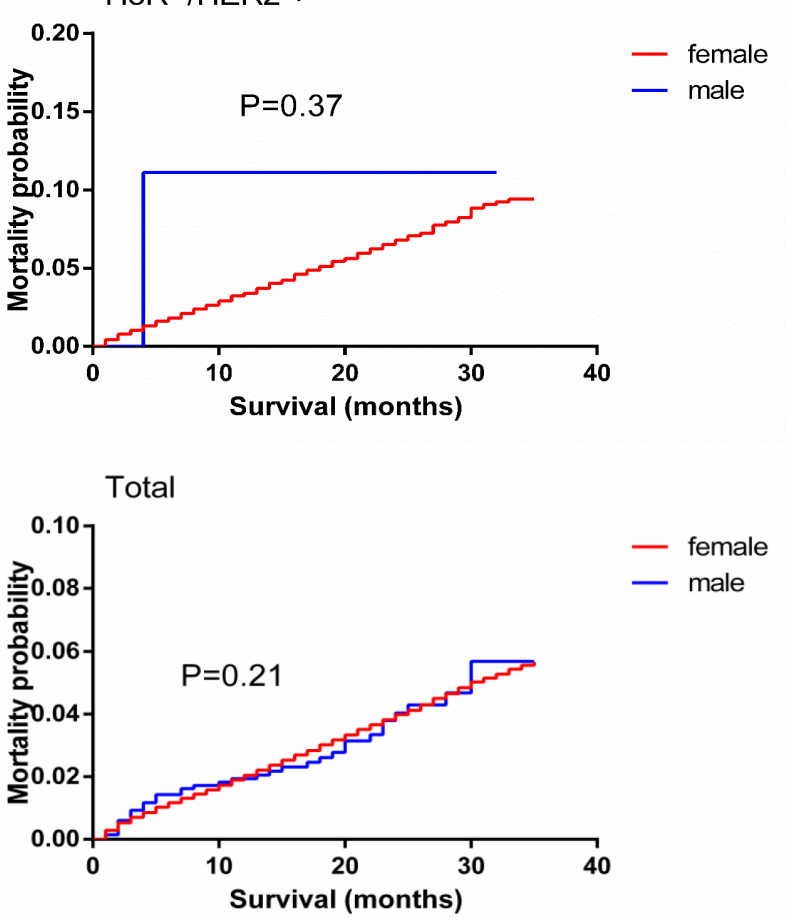

$=1.346(1.258,1.441)$ ), grade (moderately differentiated, $\mathrm{HR}=1.848$ (1.594, 2.142); poorly differentiated, HR = 3.868 (3.347, 4.471); undifferentiated, HR = 3.763 (2.833, 4.999)), tumor stage (II, HR $=1.20(0.98,1.48)$; III, HR = $1.72(1.15,2.61) ; \mathrm{IV}, \mathrm{HR}=2.19(1.88,2.60))$, tumor size $(\mathrm{T} 2, \mathrm{HR}=2.919(2.651,3.214) ; \mathrm{T} 3, \mathrm{HR}=3.139$ (2.797, $3.523)$; T4, HR = $6.984(5.211,8.963))$, node stage $(\mathrm{N} 1$, $\mathrm{HR}=1.692(1.572,1.822) ; \mathrm{N} 2, \mathrm{HR}=1.643(1.48,1.824)$; $\mathrm{N} 3, \mathrm{HR}=1.553(1.386,1.74))$, distant metastasis $(\mathrm{M} 1, \mathrm{HR}$ $=5.967(5.599,6.359))$, laterality (bilateral, HR $=1.545$ $(1.37,1.804)$ ), HER2 status (positive, HR $=1.713$ (1.658, $1.771)$ ) and history of radiation (no, $\mathrm{HR}=2.486(2.223$, 2.805)).

Table 5 summarizes the BCSM identified for MBC and FBC via the subgroup analysis. The percentages of males and females who were dying from $\mathrm{BC}$ at the end of the study were compared $(2.2 \%$ vs. $2.5 \%)$. The univariate analysis of BCSM according to tumor subtype showed
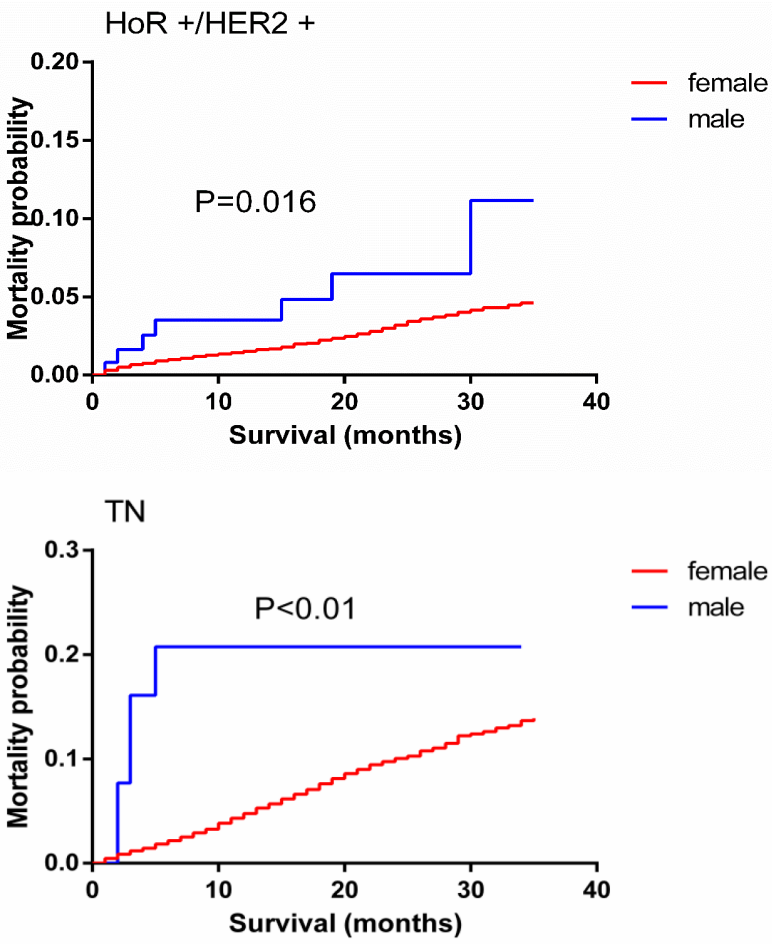

Figure 2: Breast-cancer-specific mortality curves of male matched with female breast cancer patients. 
Table 5: Breast cancer-specific mortality according to tumor subtypes between MBC and FBC

\begin{tabular}{|l|l|l|l|l|l|l|}
\hline \multicolumn{1}{|c|}{ Tumor subtype } & $\begin{array}{c}\text { Female } \\
(\mathbf{\%})\end{array}$ & $\begin{array}{c}\text { Male } \\
\mathbf{( \% )}\end{array}$ & \multicolumn{1}{c|}{ cHR 95\% CI } & \multicolumn{1}{c|}{$\boldsymbol{P}$} & \multicolumn{1}{c|}{ aHR 95\% CI } & \multicolumn{1}{c|}{$\boldsymbol{P}$} \\
\hline $\begin{array}{l}\text { HoR-positive } \\
\text { /HER2-negative }\end{array}$ & 1.7 & 1.2 & $0.881(0.539,1.441)$ & 0.38 & $0.604(0.369,0.99)$ & 0.045 \\
\hline $\begin{array}{l}\text { HoR-positive } \\
\text { /HER2-positive }\end{array}$ & 2.4 & 5.0 & $2.144(1.016,4.526)$ & 0.016 & $1.493(0.702,3.174)$ & 0.297 \\
\hline $\begin{array}{l}\text { HoR-negative/ } \\
\text { HER2-positive }\end{array}$ & 4.9 & 8.3 & $1.827(0.257,13.004)$ & 0.37 & $1.375(0.191,9.902)$ & 0.868 \\
\hline Triple negative & 6.8 & 16.1 & $3.697(1.536,8.898)$ & $<0.01$ & $3.125(1.273,7.668)$ & 0.013 \\
\hline
\end{tabular}

Reference group for each model was 'women'.

HER2 human epidermal growth factor receptor 2; HoR hormone receptor; cHR: crude hazard ratio; CI: confidence interval; aHR: adjusted hazard ratio (adjusted for age at diagnosis, race, grade, stage, tumor stage, node stage, distant metastasis, laterality and radiation).

significant differences between $\mathrm{MBC}$ and $\mathrm{FBC}$, with higher mortality in HoR-positive/HER2-positive males than females with the same subtype $(5.0 \%$ vs. $2.4 \%$, HR = $2.144(1.016,4.526), p=0.016)$. As expected for the TN subtype, BCSM was significantly greater in males $(16.1 \%)$ than females $(6.8 \%)$ at the end of the study $(\mathrm{HR}=3.697$ $(1.536,8.898), p<0.01)$. The results of the multivariate analysis were somewhat inconsistent with those of the univariate analysis, as they showed that male patients were more likely to live than females with the HoR-positive/ HER2-negative subtype $(\mathrm{HR}=0.604(0.369,0.99), p=$ $0.045)$ and have poorer survival than females with the TN subtype $(\mathrm{HR}=2.251(1.058,4.787), p=0.013)$.

\section{DISCUSSION}

$\mathrm{MBC}$ is a rare disease, and its etiology is neither completely characterized nor fully understood. In contrast with $\mathrm{FBC}$, there have been no prospective randomized studies allowing the biological characteristics of $\mathrm{MBC}$ or clinical and therapeutic approaches to be delineated with any certainty. The current knowledge base regarding MBC is derived from the data collected in retrospective studies.

Given that $\mathrm{MBC}$ is rare, there are no routine screening guidelines for men, which would delay the diagnosis $[3,14]$. Consistent with the findings of previous studies, in this study, males tended to be older than females when diagnosed $[3,15]$. The prevalence of comorbidities increased with age, which likely contributed to the decreased OS in MBC than FBC. Donegan et al. [16] reported that the high rate of post-treatment mortality from comorbidities, such as heart disease or other cancer types, was a major contributor to the poor survival observed in $\mathrm{MBC}$. In our population-based comparison, MBC had more advanced stages (stages II-IV), lower grades, larger sizes, more lymph node and distant metastases than FBC. While MBC patients had poorer OS, there was no disparity in BCSM. The univariate analysis showed that survival was generally poorer in TN MBC than TN FBC in terms of both OS and BCSM, while for the HoR-positive/HER2negative subtype, MBC had a longer survival period than
FBC in terms of BCSM.

Given that $\mathrm{MBC}$ is rare, there are no standard treatments guidelines for men, which could cause disparities in survival. Several studies have identified a higher frequency of HoR positivity in MBC than FBC, suggesting that endocrine therapy could be useful in this population. Some studies reported that endocrine therapy was associated with improved survival in men [17-19], while other studies have suggested that estrogen receptor (ER)-positive tumors in males and females do not respond to tamoxifen therapy in the same manner. As a result, HoR positivity was not indicative of a good prognosis in $\mathrm{MBC}[20,21]$. In view of the difference in BCMS observed in the HoR-positive/HER2-negative subtype, endocrine therapy might be as effective in $\mathrm{MBC}$ as in $\mathrm{FBC}$. MBC is a hormone-driven disease that often leads to androgen receptor (AR) expression, with AR expression rates reportedly ranging from 34-95\% in MBC [22-24]. Compared to $\mathrm{FBC}$, a larger fraction of $\mathrm{ER}+\mathrm{MBC}$ seem to be more connected with AR- than ER-associated signaling [25], suggesting that coordinated ER and AR expression could be relevant to MBC biology. Several subsequent reports have suggested that gonadotropin-releasing hormone analogues in combination with aromatase inhibitors could improve the survival outcome of MBC. Further investigation could lead to the discovery of antihormonal therapies based on new intrinsic subtypes, which could improve the clinical management of MBC.

Conflicting data have been reported regarding HER2 status in males as a prognostic indicator. Several studies have shown a lower expression or a lack of prognostic significance of HER2 in MBC compared with FBC, but some studies have instead demonstrated HER2 over expression in MBC [26-29]. While our analysis showed that HER2 status was a prognostic indicator for OS, there was no difference in its prognostic effect between male and female survival. Thus, despite the similar expression of biomarkers, MBC might yet be biologically different from $\mathrm{FBC}$ in other ways.

Triple-negative breast cancers (TNBCs) are a heterogeneous group of tumors with higher relapse rates 
and shorter OS in the metastatic setting. As expected, in the TN subtype, survival was significantly different between the sexes. From a genetic perspective, tumors arising in carriers of BReast CAncer (BRCA) genes are similar to TNBCs in many ways. After BRCA2 was identified, BRCA2 mutations were found in families affected by both FBC and MBC. BRCA2 mutations have been found to significantly increase the risk of MBC [30] and identified as independent, adverse prognostic factors in MBC [31]. Additionally, approximately $20 \%$ of patients with $\mathrm{MBC}$ were found to have a family history of $\mathrm{BC}$ [32]. Other genetic alterations that have been connected with the onset of MBC involve PALB2, CYP17, CHEK2, and RAD51B [33]. A new class of agents has shown promising activity in BRCA-deficient BC patients, such as DNAdamaging cytotoxic agents (e.g., cisplatin) and targeting poly(ADP-ribose) polymerase inhibitors (e.g., olaparib) $[34,35]$. The association observed between MBC and BRCA-deficient disease suggests the potential therapeutic applicability of olaparib, cisplatin and other related agents in this condition, although this clearly requires further clinical validation.

The molecular characterization of MBC has offered insights into potential therapeutic strategies. In one report [36], immunohistochemistry analyses showed higher expression levels of homeobox D10 (HOXD10) and vascular endothelial growth factor (VEGF) in MBC than FBC specimens. HOXD10 is involved in cell migration and extracellular matrix remodeling. Meanwhile, VEGF is a driver of tumor-related angiogenesis; several agents (e.g., bevacizumab) can antagonize VEGF-mediated signaling and improve progression-free survival when combined with cytotoxic chemotherapy for treating metastatic FBC [37]. Given these data, the exploration of VEGF-directed therapies for MBC might be warranted. In a series of 30 patients with male gynecomastia and 30 patients with $\mathrm{MBC}$, prolactin receptor expression was significantly higher in the MBC patients than in the patients with gynecomastia [38]. Compounds antagonizing the prolactin receptor have been shown to augment the activity of doxorubicin and paclitaxel in cellular models; as such, this approach might be clinically useful for treating MBC [39].

Our study has some limitations. Because SEER collected information about HER2 status since 2010, our analysis had a short follow-up period, which might affect the interpretation of our results. We did not have information for this cohort regarding systemic treatments, such as surgery and chemotherapy, which might contribute to some of the differences observed in survival according to tumor subtype. However, the male patients in this study were less likely to receive radiation than females.

In summary, we identified clear differences between MBC and FBC in both OS and BCSM in the TN subtype, which warrant further investigation. Future translational studies require prospective validation and should focus on the tumor biology and treatment efficacy of MBC. However, our study has laid a foundation for using tumor subtype differences between the sexes to develop and evaluate personalized therapies for MBC in clinical trials.

\section{MATERIALS AND METHODS}

\section{Data source and study design}

We obtained data from the National Cancer Institute's SEER program between 2010 and 2012. SEER started collecting information on HER2 status in 2010. Therefore, we used that year as the starting point for our study. We extracted data for all cases of invasive BC diagnosed between 2010 and 2012. We selected cases with known HoR and HER2 statuses.

The demographic variables included age at diagnosis $(<35,35-49,50-64,>65$ years) and race (white, black, other). The cancer characteristics included stage (I, II, III, IV, unknown), grade (well differentiated, moderately differentiated, poorly differentiated, undifferentiated, unknown), T stage (T0/T1, T2, T3, T4, NA), N stage (N0, N1, N2, N3, NX, NA), distant metastasis (M0, M1, NA), laterality (right, left, paired, bilateral, unknown), and HoR and HER2 status (positive, negative, borderline, unknown). The treatment characteristics included receipt of radiation therapy (no, yes, unknown). Tumor subtypes were classified as HoR-positive/HER2-negative, HoRpositive/HER2-positive, HoR-negative/HER2-positive, and triple-negative (TN) subtypes according to the breast subtype variable.

The two main outcomes in our study were OS and BCSM. Vitality status was recorded as "alive" or "dead" in the SEER dataset. Survival time (in months) was calculated for each patient using the "Completed Months of Follow-up" option in the SEER database. OS was determined by comparing males and females who were alive at the end of the study period or who were alive at their last follow-up. BCSM was determined by comparing males and females whose cause of death was due to BC with males and females who were alive at the end of the study period, had died due to other causes, or who were alive at their last follow-up. Cases without survival times were classified as unknown and removed from the study.

\section{Statistical analysis}

Patient demographics and cancer- and treatmentrelated characteristics were compared between females and males using Chi square or Fisher's exact tests as appropriate. Within each variable, patients with unknown data were excluded from the comparative analysis. A matched subgroup analysis was performed. Survival probabilities for OS and BCSM were estimated using 
the Kaplan-Meier method, and variables were compared using the log-rank test in the subgroups. Univariate and multivariate Cox proportional hazard regressions were used to obtain HRs and their respective 95\% confidence intervals and show the strength of the estimated relative risk; these approaches were applied to model the relationship between potential covariates and either OS or BCSM. All statistical analyses were performed using SPSS 19.0 (IBM Corporation, Armonk, NY), and all charts of survival probabilities were prepared using GraphPad Prism 6.0. Two-sided p values less than 0.05 were considered statistically significant.

\section{ACKNOWLEDGMENTS}

This work was partially supported by a NSFC grant to Dr. Shengrong Sun (Grant NO: 81471781). This work was also supported by a NSFC grant to Dr. Juanjuan Li (Grant NO: 81302314) the Fundamental Research Funds of Hubei Province Health and Family Planning Commission to Wen Wei (Grant NO: JS-20110118) and the Fundamental Research Funds for the Central Universities of China to Shan Zhu (Grant NO: 2042014kf0189).

\section{CONFLICTS OF INTEREST}

The authors have no conflicts of interest to disclose.

\section{REFERENCES}

1. Fentiman IS, Fourquet A and Hortobagyi GN. Male breast cancer. Lancet. 2006; 367:595-604.

2. Siegel RL, Miller KD and Jemal A. Cancer statistics, 2016. CA: a cancer journal for clinicians. 2016; 66:7-30.

3. Giordano SH, Cohen DS, Buzdar AU, Perkins G and Hortobagyi GN. Breast carcinoma in men: a populationbased study. Cancer. 2004; 101:51-57.

4. Speirs V and Shaaban AM. The rising incidence of male breast cancer. Breast cancer research and treatment. 2009; 115:429-430.

5. Stang A and Thomssen C. Decline in breast cancer incidence in the United States: what about male breast cancer? Breast cancer research and treatment. 2008; 112:595-596.

6. Anderson WF, Jatoi I, Tse J and Rosenberg PS. Male Breast Cancer: A Population-Based Comparison With Female Breast Cancer. J Clin Oncol. 2010; 28:232-239.

7. Kwong A, Chau WW, Mang OWK, Wong CHN, Suen DTK, Leung R, Wong K, Lee A, Shea C, Morse E, Law SCK and Grp HKBCR. Male Breast Cancer: A PopulationBased Comparison with Female Breast Cancer in Hong Kong, Southern China: 1997-2006. Annals of surgical oncology. 2014; 21:1246-1253.

8. Gomez-Raposo C, Tevar FZ, Moyano MS, Gomez ML and
Casado E. Male breast cancer. Cancer treatment reviews. 2010; 36:451-457.

9. La Verde N, Collova E, Lonardi S, Generali D, Moretti A, Atzori F, Cazzaniga M, Saggia C, Tondulli L, Marcon I, Gentile AL, Rossello R, Martelli O, et al. Male breast cancer: clinical features and multimodal treatment in a retrospective survey analysis at Italian centers. Tumori. 2013; 99:596-600.

10. Ottini L, Palli D, Rizzo S, Federico M, Bazan V and Russo A. Male breast cancer. Crit Rev Oncol Hemat. 2010; 73:141-155.

11. Anan K, Mitsuyama S, Nishihara K, Abe Y, Iwashita T, Ihara T, Tamae K, Ono M and Toyoshima S. Breast cancer in Japanese men: does sex affect prognosis? Breast cancer (Tokyo, Japan). 2004; 11:180-186.

12. Hill TD, Khamis HJ, Tyczynski JE and Berkel HJ. Comparison of male and female breast cancer incidence trends, tumor characteristics, and survival. Ann Epidemiol. 2005; 15:773-780.

13. Thalib L and Hall P. Survival of male breast cancer patients: Population-based cohort study. Cancer Sci. 2009; 100:292295.

14. Salvadori B, Saccozzi R, Manzari A, Andreola S, Conti RA, Cusumano F and Grassi M. Prognosis of breast cancer in males: an analysis of 170 cases. European journal of cancer. 1994; 30A:930-935.

15. Nahleh ZA, Srikantiah R, Safa M, Jazieh AR, Muhleman A and Komrokji R. Male breast cancer in the veterans affairs population: a comparative analysis. Cancer. 2007; 109:1471-1477.

16. Donegan WL, Redlich PN, Lang PJ and Gall MT. Carcinoma of the breast in males: a multiinstitutional survey. Cancer. 1998; 83:498-509.

17. Eggemann $\mathrm{H}$, Ignatov $\mathrm{A}$, Smith BJ, Altmann U, von Minckwitz G, Rohl FW, Jahn M and Costa SD. Adjuvant therapy with tamoxifen compared to aromatase inhibitors for 257 male breast cancer patients. Breast cancer research and treatment. 2013; 137:465-470.

18. Giordano SH, Perkins GH, Broglio K, Garcia SG, Middleton LP, Buzdar AU and Hortobagyi GN. Adjuvant systemic therapy for male breast carcinoma. Cancer. 2005; 104:2359-2364.

19. Ribeiro G and Swindell R. Adjuvant tamoxifen for male breast cancer (MBC). British journal of cancer. 1992; 65:252-254.

20. Goss PE, Reid C, Pintilie M, Lim R and Miller N. Male breast carcinoma: a review of 229 patients who presented to the Princess Margaret Hospital during 40 years: 1955-1996. Cancer. 1999; 85:629-639.

21. Wang-Rodriguez J, Cross K, Gallagher S, Djahanban M, Armstrong JM, Wiedner N and Shapiro DH. Male breast carcinoma: correlation of ER, PR, Ki-67, Her2-Neu, and p53 with treatment and survival, a study of 65 cases. Modern pathology. 2002; 15:853-861. 
22. Hill A, Yagmur Y, Tran KN, Bolton JS, Robson M and Borgen PI. Localized male breast carcinoma and family history. An analysis of 142 patients. Cancer. 1999; 86:821825 .

23. Hsing AW, McLaughlin JK, Cocco P, Co Chien HT and Fraumeni JF, Jr. Risk factors for male breast cancer (United States). Cancer causes \& control. 1998; 9:269-275.

24. Wenhui Z, Shuo L, Dabei T, Ying P, Zhipeng W, Lei Z, Xiaohui H, Jingshu G, Hongtao S and Qingyuan Z. Androgen receptor expression in male breast cancer predicts inferior outcome and poor response to tamoxifen treatment. European journal of endocrinology / European Federation of Endocrine Societies. 2014; 171:527-533.

25. Ottini L, Silvestri V, Rizzolo P, Falchetti M, Zanna I, Saieva C, Masala G, Bianchi S, Manoukian S, Barile M, Peterlongo P, Varesco L, Tommasi S, et al. Clinical and pathologic characteristics of BRCA-positive and BRCA-negative male breast cancer patients: results from a collaborative multicenter study in Italy. Breast cancer research and treatment. 2012; 134:411-418.

26. Avisar E, McParland E, Dicostanzo D and Axelrod D. Prognostic factors in node-negative male breast cancer. Clinical breast cancer. 2006; 7:331-335.

27. Onami S, Ozaki M, Mortimer JE and Pal SK. Male breast cancer: an update in diagnosis, treatment and molecular profiling. Maturitas. 2010; 65:308-314.

28. Rudlowski C, Friedrichs N, Faridi A, Fuzesi L, Moll R, Bastert G, Rath W and Buttner R. Her-2/neu gene amplification and protein expression in primary male breast cancer. Breast cancer research and treatment. 2004; 84:215223.

29. Schaub NP, Maloney N, Schneider H, Feliberti E and Perry R. Changes in male breast cancer over a 30 -year period. The American surgeon. 2008; 74:707-711; discussion 711-702.

30. Easton DF, Steele L, Fields P, Ormiston W, Averill D, Daly PA, McManus R, Neuhausen SL, Ford D, Wooster R, Cannon-Albright LA, Stratton MR and Goldgar DE. Cancer risks in two large breast cancer families linked to BRCA2 on chromosome 13q12-13. American journal of human genetics. 1997; 61:120-128.
31. Kwiatkowska E, Teresiak M, Filas V, Karczewska A, Breborowicz D and Mackiewicz A. BRCA2 mutations and androgen receptor expression as independent predictors of outcome of male breast cancer patients. Clinical cancer research. 2003; 9:4452-4459.

32. Ottini L. Male breast cancer: a rare disease that might uncover underlying pathways of breast cancer. Nature Reviews Cancer. 2014; 14:643-644.

33. Ruddy KJ and Winer EP. Male breast cancer: risk factors, biology, diagnosis, treatment, and survivorship. Annals of oncology. 2013; 24:1434-1443.

34. Byrski T, Dent R, Blecharz P, Foszczynska-Kloda M, Gronwald J, Huzarski T, Cybulski C, Marczyk E, Chrzan R, Eisen A, Lubinski J and Narod SA. Results of a phase II open-label, non-randomized trial of cisplatin chemotherapy in patients with BRCA1-positive metastatic breast cancer. Breast cancer research. 2012; 14:R110.

35. Annunziata CM and Bates SE. PARP inhibitors in BRCA1/ BRCA2 germline mutation carriers with ovarian and breast cancer. F1000 biology reports. 2010; 2.

36. Bartel DP. MicroRNAs: genomics, biogenesis, mechanism, and function. Cell. 2004; 116:281-297.

37. Miller K, Wang M, Gralow J, Dickler M, Cobleigh M, Perez EA, Shenkier T, Cella D and Davidson NE. Paclitaxel plus bevacizumab versus paclitaxel alone for metastatic breast cancer. The New England journal of medicine. 2007; 357:2666-2676.

38. Ferreira M, Mesquita M, Quaresma M and Andre S. Prolactin receptor expression in gynaecomastia and male breast carcinoma. Histopathology. 2008; 53:56-61.

39. Howell SJ, Anderson E, Hunter T, Farnie G and Clarke RB. Prolactin receptor antagonism reduces the clonogenic capacity of breast cancer cells and potentiates doxorubicin and paclitaxel cytotoxicity. Breast cancer research. 2008; 10:R68. 